\title{
Durability Properties of concrete incorporating calcined Phyllite
}

\author{
Dalpat Singh Chundawat ${ }^{* 1}$, Sandeep Kumar Tomar², Dinesh Kumar Sharma ${ }^{3}$ \\ JK Lakhsmipat University Jaipur, Rajasthan ${ }^{123}$ \\ E -Mail: dschundawat@1c.jkmail.com, dinesh.sharma@jklu.edu.in, sandeeptomar@gmail.com.
}

\begin{abstract}
The environmental and economic concern is the biggest challenge that concrete industry is facing today. Advancement in utilization of wastes in concrete as a mixture reduces usage of natural resources. Phyllite is a kind of foliated metamorphic rock generates during underground mining .Phyllite was calcined at 850 to $900^{\circ} \mathrm{C}$ in furnace and ground in ball mill. In this study, cement was partially replaced by weight with calcined phyllite to make M30 grade of concrete with 0\% (Control mix), 2\%, 4\%, 6\%, 8\%, \& 10\%, (which are designated as M1, M2, M3, M4, M5 and M6). The laboratory tests such as slump value, compressive strength, flexural strength, water absorption, chloride ion penetration and durability in acidic and basic medium were conducted on the phyllite concrete and results are compared with the control mix. Through results it is concluded that cement can be replaced in concrete at the tune of $8 \%$ with Calcine Phyllite (CP) without affecting the strength and durability.

The aim of the experiment is to find the maximum content of mines calcined Phyllite that can be used as a partial replacement of cement without compromising the quality on any of the characteristics of concrete.
\end{abstract}

Key words: Cement, Concrete, Calcined Phyllite, Compressive Strength, Flexural Strength 


\section{Introduction}

Around the world, calcined phyllite (CP) is an active pozzolanic admixtures which is used for reducing the cement content in mortar and concrete production. The raw phyllite was procured from the lime stone mine situated at village Basantgarh, Rajasthan (India) which is created from slate which primarily compose of Quartz, Hematite, Muscovite, Albite, Anorthite, Microcline.

Adom-Asamoah \& Afrifa used phyllite coarse aggregate in concrete which showed 15-20\% lower compressive and flexural strength as compared to conventional granite aggregate concrete [1]. Various studies indicated reduced quality of mortar due to incorporation of phyllite, however phyllite clay can be used due to the saving in cost and low energy consumption in production of mortar [2, 3, 4]. The ductility, flexural strength and shear strength of phyllite RC beams got decreased as compared to conventional aggregate beams [5]. Phyllite is found suitable to be used as sealing liner in irrigation ponds and as core material of small earth-zoned dams [6]. Schulze \& Rickert recommended based on their study that appropriately calcined clay could be used as a supplementary cementitious material [7].

No research work has been found so far to study the effect of calcined phyllite on the properties of concrete. Looking to the availability of phyllite in abundance, the main objectives of the present research is to investigate its effect on strength and durability of concrete by the partial replacement of cement. Therefore, it is a novel work in the direction of utilization of phyllite waste material in the manufacture of concrete by the partial replacement of cement.

\section{Materials and Experimental Program}

\subsection{Materials}

Ordinary Portland cement 43 grade conforming to IS: 269:2015 was used in the study. Banas river sand was used as fine aggregate. Coarse aggregates $(20 \mathrm{~mm}$ and $10 \mathrm{~mm}$ size) were procured from locally available commercial quarry. The phyllite was procured from the limestone mine situated at village Basantgarh, Rajasthan (India). Figure -1 shows the phyllite waste lying at mine site. The 
phyllite was procured from the lime stone mine situated at village Basantgarh, Rajasthan (India)which is created from slate, that is further metamorphosed and very fine grained white mica achieved a preferred orientation. Calcined Phyllite and Normal Phyllite are shown in Figure -2. The chemical composition of cement, raw phyllite and calcined phyllite are shown in Table-1.It primarily compose of quartz, sericite mica, and chlorite. In this study, cement has been replaced by CP in M30 grade of concrete. Particle Size distribution of Cement and Calcined Phyllite are shown in Figure -3.

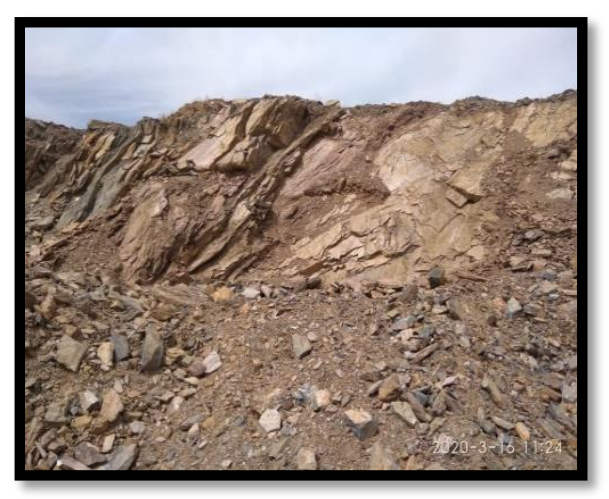

Figure 1: of Raw Phyllite Deposits

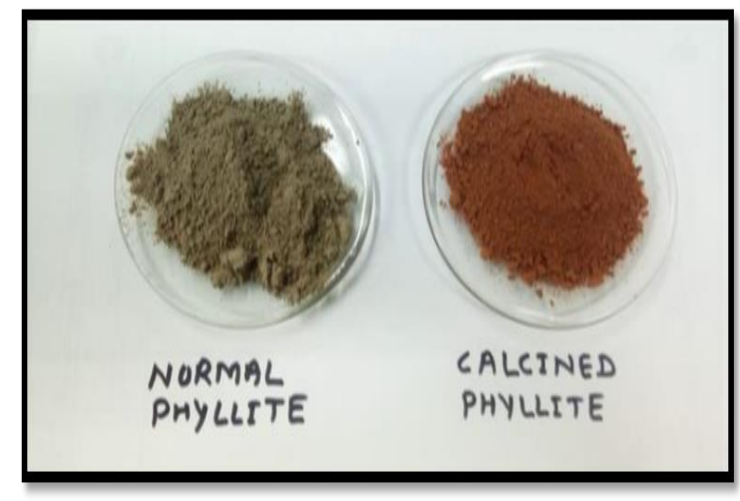

Figure 2: Normal Phyllite \& Calcined

Table 1: Chemical composition of cement, phyllite and calcined phyllite

\begin{tabular}{|l|l|l|l|l|l|l|l|l|l|l|}
\hline Parameters & $\begin{array}{l}\mathrm{LOI} \\
(\%)\end{array}$ & $\begin{array}{l}\mathrm{SiO}_{2} \\
(\%)\end{array}$ & $\begin{array}{l}\mathrm{Al}_{2} \mathbf{O}_{3} \\
(\%)\end{array}$ & $\begin{array}{l}\mathrm{Fe}_{2} \mathrm{O}_{3} \\
(\%)\end{array}$ & $\begin{array}{l}\mathrm{CaO} \\
(\%)\end{array}$ & $\begin{array}{l}\mathrm{MgO} \\
(\%)\end{array}$ & $\begin{array}{l}\mathrm{Na}_{2} \mathrm{O} \\
(\%)\end{array}$ & $\begin{array}{l}\mathrm{K}_{2} \mathrm{O} \\
(\%)\end{array}$ & $\begin{array}{l}\mathrm{SO3} \\
(\%)\end{array}$ & $\mathbf{C l}(\%)$ \\
\hline Cement & 3.5 & 21.32 & 5.72 & 3.60 & 60.59 & 2.27 & 0.45 & 0.90 & 2.64 & 0.00 \\
\hline Phyllite & 10.98 & 38.39 & 18.62 & 11.05 & 17.01 & 1.54 & 0.12 & 1.60 & 0.12 & 0.026 \\
\hline $\begin{array}{l}\text { Calcined } \\
\text { phyllite }\end{array}$ & 0.20 & 41.54 & 19.62 & 12.70 & 18.03 & 1.64 & 0.13 & 1.64 & 0.14 & 0.027 \\
\hline
\end{tabular}




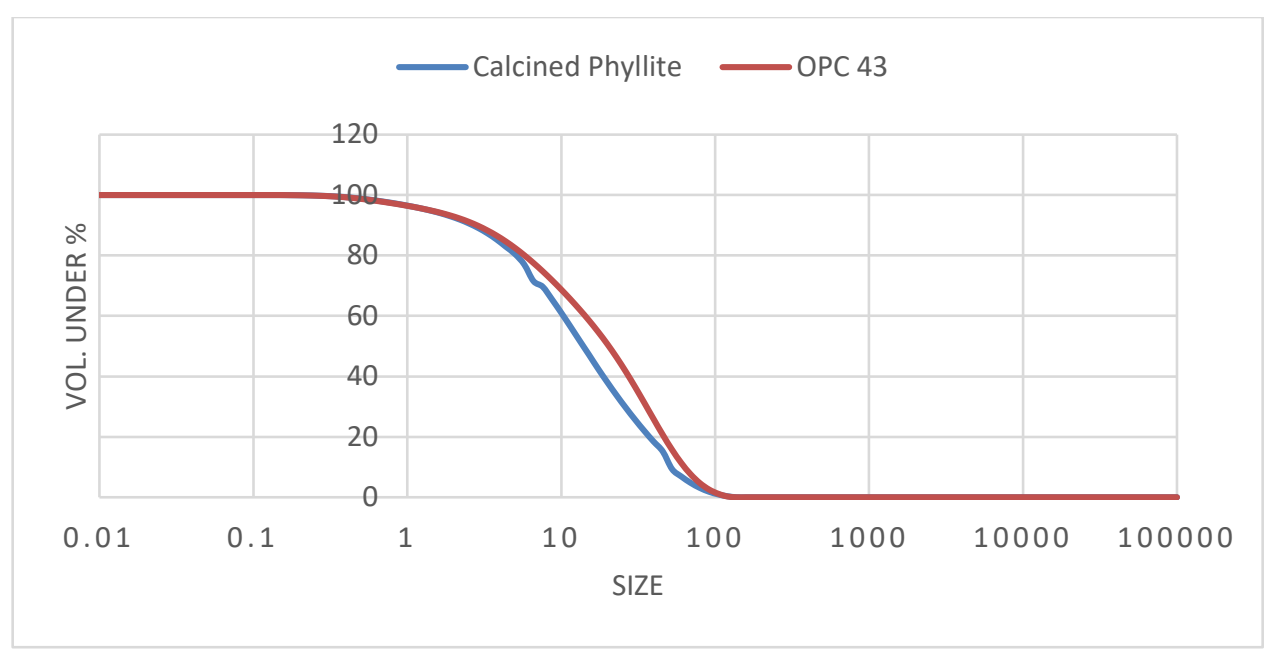

Figure -3

\subsection{Experimental Method}

\subsubsection{Determination of Compressive strength test}

Compressive strength was conducted on cube specimens of $150 \mathrm{~mm}$ size at an age of 7, 28, and 56 days. Fifty-Four cubes were tested for CST as taking avg. of three cubes for each design mix for CST of all mixes to find the average compressive strength.

\subsubsection{Determination of Flexural strength test}

Flexural strength was prepared of 36 beam specimens of size $500 \mathrm{~mm} \times 100 \mathrm{~mm} \times 100 \mathrm{~mm}$. Flexural strength of three specimens for each design mix and tested at the age of 7 and 28 days. Freshly mixed concrete was filled in three layers and each layer was compacted manually by 150 strokes using a $25 \mathrm{~mm}$ diameter steel tamping rod. The hardened beam specimens were tested using automatic universal testing machine $\&$ average of three specimens was reported flexural strength of that mix. Flexural strength test was conducted as per IS 516-1959.

\subsubsection{Determination of Water absorption test}

Water absorption is measured by measuring the increase in mass as a percentage of dry mass. Water absorption test was carried out as per IS 2386(Part 3):1963. Different pore size leads to different capillary pressure, in order to consider surface effect, both surface water absorption and 
internal water absorption were investigated. Water absorption is measured by measuring the increase in mass as a percentage of dry mass as per Indian standard.

\subsubsection{Determination of Rapid Chloride Ion Penetration Test}

Rapid chloride ion penetration test was performed at 28days and 90 days' concrete as per recommendations of ASTM C 1202. The amount of electrical current passed through $50 \mathrm{~mm}$ thick slices of $100 \mathrm{~mm}$ nominal diameter cores during a 6-hour period is monitor in the test. A potential difference of 60 volts direct current is maintained across the ends of the specimen, one of which is immersed in a sodium chloride solution, the other in a sodium hydroxide solution. The total charge passed, in coulombs, has been found to be related with the resistance of the concrete specimen to chloride ion penetration. Durability Test of concrete structures made up of blank and structures with $8 \%$ replaced Calcined phyllite were test for 28 days in harsh environment of acid and alkaline nature. Cubes were cured in normal water, $\mathrm{NaCl}$ solution and 1:2 $\mathrm{H} 2 \mathrm{SO} 4$ acid solution to analyze and conclude concrete properties.

\subsubsection{Determination of Durability Test in Acid Medium}

Durability test both in acid \& basic medium was conducted to address the issue of corrosion in reinforcement of RC structures and results were compared with the results of neutral environment specimens. This test was conducted only on the concrete mixes M1 (control mix) and M5 (8\% CP concrete).

\section{Concrete mix design and workability}

In this research, M30 grade of concrete was designed as per guidelines of IS:10262:2009. The combined gradation curve along with upper and lower limits specified by IS: 383-2016 are shown in Figure 4. Six different concrete mix proportions by replacing cement with $0 \%$ (control mix), $2 \%, 4 \%, 6 \%, 8 \%$ and $10 \%$ (weight \%) CP are denoted as M1, M2, M3, M4, M5 and M6 respectively. The mix proportions and slump values are shown in Table 2. 


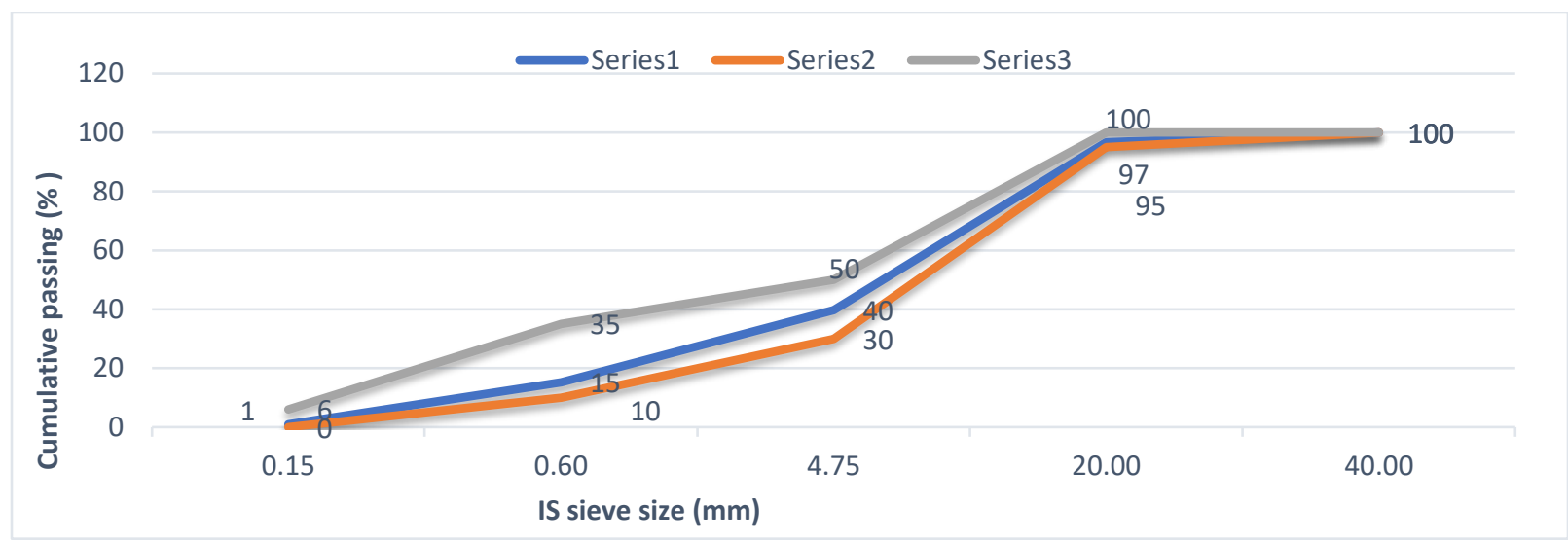

Figure 4: Combined gradation curve

Table 2: Concrete mix proportions and workability

\begin{tabular}{|c|c|c|c|c|c|c|}
\hline Particulars & M1 & M2 & M3 & M4 & M5 & M6 \\
\hline w/c ratio & 0.41 & 0.41 & 0.41 & 0.41 & 0.41 & 0.41 \\
\hline Cement $\left(\mathrm{kg} / \mathrm{m}^{3}\right)$ & 420.00 & 411.60 & 403.20 & 394.80 & 386.40 & 378.42 \\
\hline Phyllite $\left(\mathrm{kg} / \mathrm{m}^{3}\right)$ & 0.00 & 8.40 & 16.80 & 25.20 & 33.60 & 42.00 \\
\hline Water (kg) & 189.00 & 189.00 & 189.00 & 189.00 & 189.00 & 189.00 \\
\hline FA $\left(\mathbf{k g} / \mathbf{m}^{3}\right)$ & 711.00 & 710.00 & 709.00 & 708.00 & 706.00 & 705.00 \\
\hline CA $20 \mathrm{~mm}\left(\left(\mathrm{~kg} / \mathrm{m}^{3}\right)\right.$ & 695.00 & 694.00 & 693.00 & 692.00 & 690.00 & 689.00 \\
\hline CA $10 \mathrm{~mm}(\mathrm{~kg} / \mathrm{m} 3$ & 460.00 & 459.00 & 459.00 & 458.00 & 457.00 & 456.00 \\
\hline $\begin{array}{l}\text { Admixture } \\
\text { (KUNNA PLAST } \\
\text { PC-100) \% }\end{array}$ & 2.100 & 2.100 & 2.100 & 2.100 & 2.100 & 2.100 \\
\hline $\begin{array}{l}\text { Wet Density } \\
\left(\mathrm{kg} / \mathrm{m}^{3}\right)\end{array}$ & 2477 & 2474 & 2472 & 2469 & 2464 & 2461 \\
\hline Slump (mm) & 135 & 130 & 130 & 125 & 125 & 125 \\
\hline
\end{tabular}

\section{Results and discussion}

The phyllite is thermally treated for calcinations in a muffle furnace at $850^{\circ} \mathrm{C}$ for two hours to ensure transformation to amorphous state of its minerals, it was observed that the Lime Reactivity 
of calcined phyllite has increased to almost thrice of raw phyllite. This further increases the pozzolanic property of the material making it suitable to react with free lime content to form secondary C-S-H gel which plays a vital role to increase the durability \& strength of cement in later stages. Clinker content in cement has certain amount of unreacted free lime which if not bound with some pozzolanic material can cause unsoundness in structure due to the formation of $\mathrm{Ca}(\mathrm{OH}) 2$ when reacted with water and ambient air. In order to control this we have added calcined phyllite as supplementary cementitious material that acts as a pozzolana and reacts with the available free lime to form secondary Calcium Silicate Hydrated Gel also known as C-S-H Gel. This phenomena fills up all the pores and voids present in the concrete and increase the density of structure making it damp. This subsequently resulted into the increasing compressive strength and Flexural Strength of Concrete structure. In our experimental analysis we observed that upto the addition of $8 \%$ of Calcined Phyllite all the available free lime has been consumed it but if the quantity of $\mathrm{CP}$ is further increase than $8 \%$ then it will act as impurity in the form of quartz silica and as no more free lime is present to react thus the strength of structure will gradually begin to decrease.

Compressive strength results at 7, 28 and 56 days are represented in Figure 5. It can be seen from the figure that compressive strength at all ages increase with the increase of CP proportion from $2 \%$ to $8 \%$. Further increase in proportion of $\mathrm{CP}$ i.e. concrete with $10 \% \mathrm{CP}$, the strength decrease at all ages but remained more than the values of control mixes. The increase of compressive strength in concrete mix M5 as compared to M1 (control mix) at the ages of 7, 28 and 56 days were $44 \%, 28 \%$ and $33 \%$ respectively. The higher rate of increase in strength at early age can reduce the formwork removal duration in RC structures.

\section{Compressive Strength of M-30 Grade Concrete}

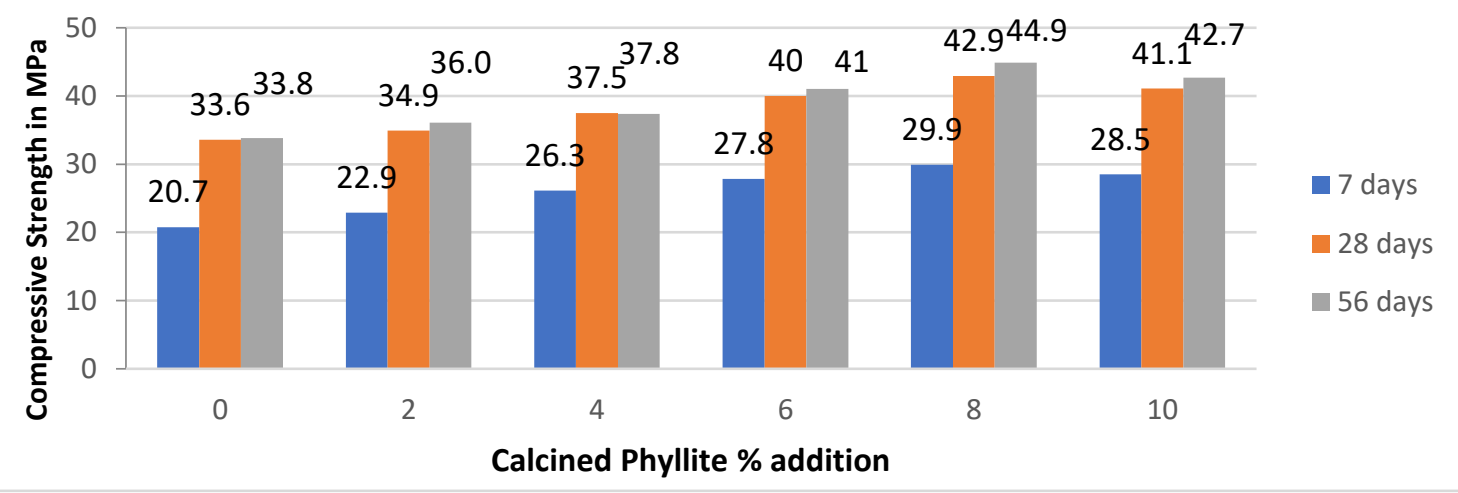

Figure 5: Variation of compressive strength with calcined phyllite 
Flexural strength results at 7 and 28 days (Figure 6) exhibited a similar trend as of compressive strength results. With the increase in $\mathrm{CP}$ content, flexural strength increased up to $8 \%$ replacement level and then got decreased for all ages of concrete. The flexural strength increased from 3.3 MPa (mix M1) to 4.2 MPa (mix M5) at the age of 7 days and from 4.2 MPa (mix M1) to 5.3 MPa (mix M5) at the age of 28 days. The flexural strength also got decreased in mix M6 but remained more than the value of mix M1 (control mix). The increase in flexural strength of concrete mix with $8 \%$ $\mathrm{CP}$ (mix M5) as compared to corresponding control mix (mix M1) were $27 \%$ and $26 \%$ at the ages of 7 and 28 days respectively which is comparable.

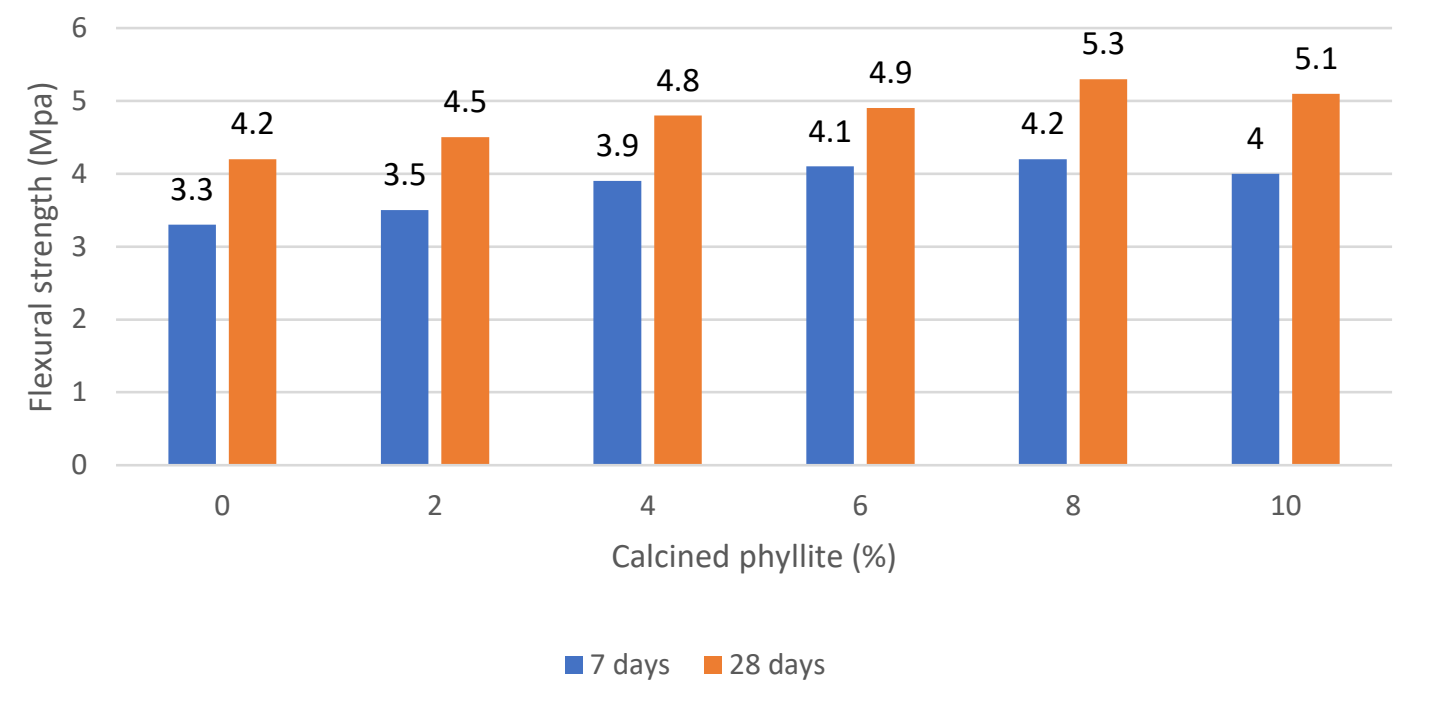

Figure 6 Variation of flexural strength with calcined phyllite

The increase in compressive strength and flexure strength by the replacement of cement with CP might be since clinker in cement has certain amount of unreacted free lime which reacts with $\mathrm{CP}$ and form secondary calcium silicate hydrated (C-S-H) gel. The C-S-H gel thus formed fills all the pores and voids present in the concrete by virtue of which strength of concrete increases up to replacement level of $8 \%$. Beyond $8 \%$ substitution of cement by $\mathrm{CP}$, all available free lime might be consumed, hence it might act as impurity in the form of quartz silica by virtue of which strength got decreased.

Water absorption test was carried out for mixes M1 and M6 at ages of $7 \& 28$ days where the water absorption of mix M6 got decreased by $22.78 \%$ and $33.53 \%$ as compared to corresponding mixes 
M1 at the age of 7 and 28 days, respectively. This proves that concrete mix with $8 \%$ calcined phyllite is dense in nature and restricts capillary action to certain extent.

The resistance to chloride ion penetration at 28 days and 90 days age of concrete for mixes M1 and M5 measured in terms of electric current passed through the specimens in coulombs are shown in Figure 7. The graph shows that total charge passed decreases from 3895 to 453 coulombs in the mixes M1 to M5 at 28 days age of concrete. Also at 90 days' age of concrete, the value decreases from 2411 to 389 coulomb. The mixes with $8 \% \mathrm{CP}$ showed lower values of charge passed as compared to corresponding control mix (0\% CP) at both ages (28 and 90 days) indicating higher resistance to chloride ion penetration. As per ASTM C 1202, coulomb values in between 100-1000 indicate very low penetrability concrete, hence the concrete with optimal $\mathrm{CP}$ content is less permeable and can be used for structural purpose as well.

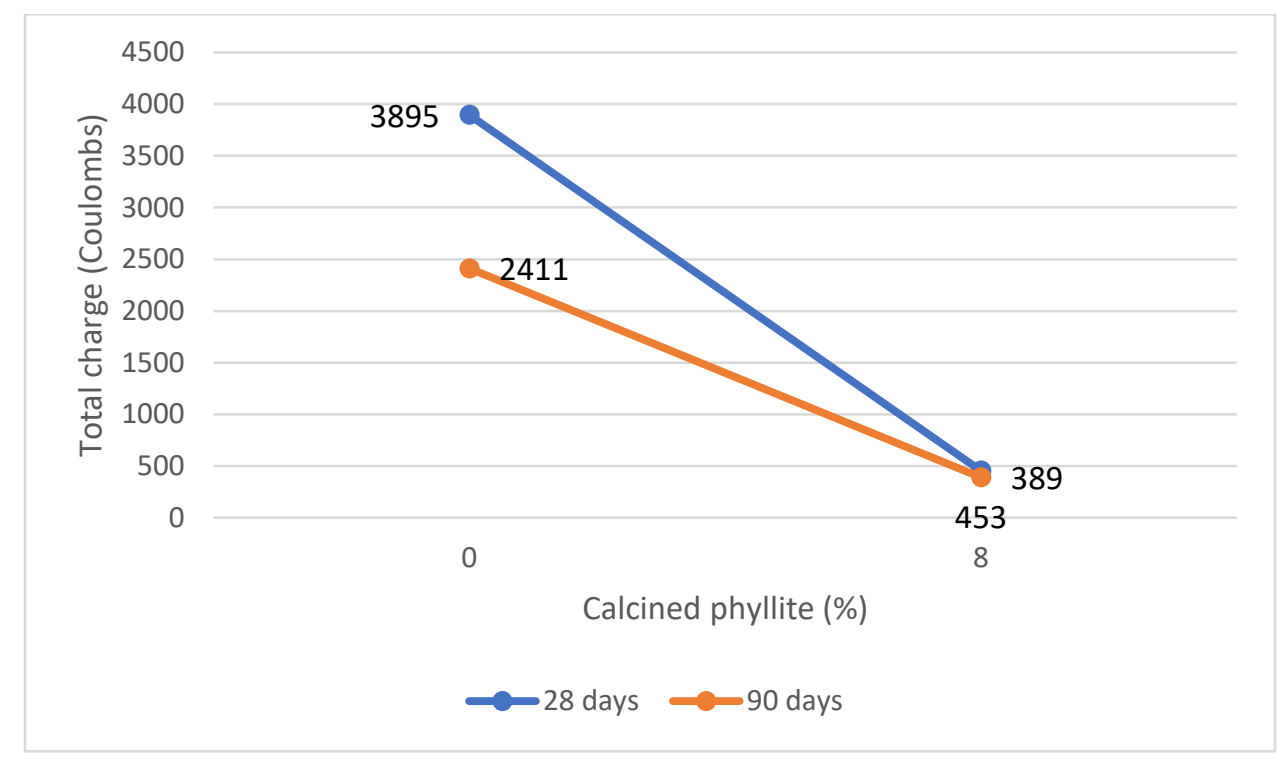

Figure 7: Rapid chloride ion penetration test results

The test results are shown in Figure 8. The test results of durability show that after curing in acidic medium for 28days M1 has decreased in strength by $11.24 \%$ whereas concrete with $8 \% \mathrm{CP}$ has decreased just $5 \%$. Also in alkaline medium for 28days M1 has decreased in strength by $23.46 \%$ whereas concrete with $8 \% \mathrm{CP}$ has decreased just $11.65 \%$. 


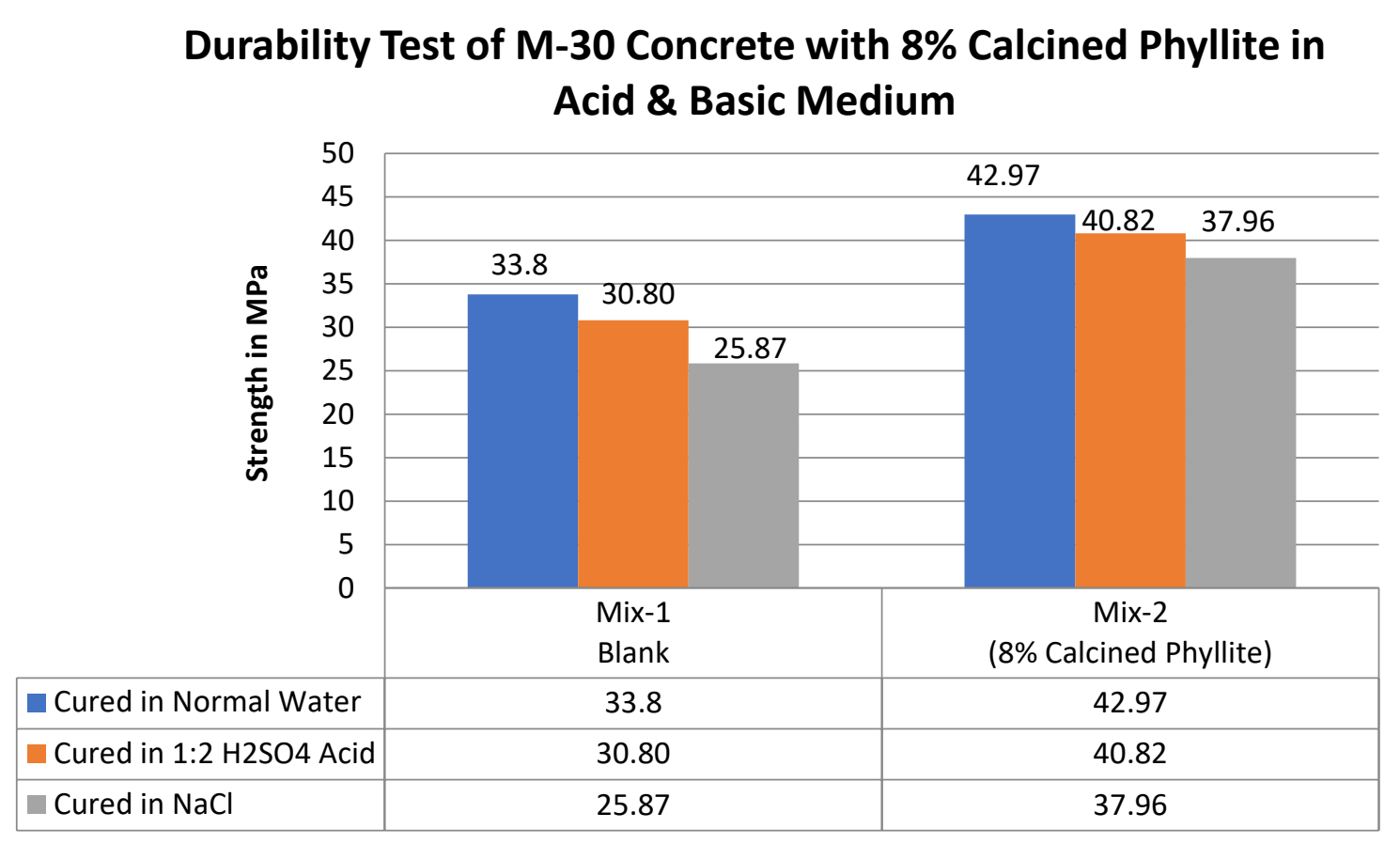

Figure 8: Durability test results

\section{Conclusions}

The key findings based on this experimental investigation are as follows:

1. The compressive strength and flexural strength of phyllite concrete increased significantly up to $8 \%$ substitution of cement by $\mathrm{CP}$ at all ages, however rate of increase in 7-day strength was more as compared to other aged concrete.

2. Chloride-ion penetration test results showed lower values of charge passed in the concrete mix with $8 \% \mathrm{CP}$ as compared to corresponding control mixes $(0 \% \mathrm{CP})$ at both ages (28 and 90 days), indicating higher resistance to chloride ion penetration in $\mathrm{CP}$ concrete.

3. Durability test in acidic and basic medium showed better durability of $8 \% \mathrm{CP}$ concrete as compared to control mix. 
Based on above test results, it is recommended to use calcined phyllite in concrete by substituting cement in the tune of $8 \%$. The bulk utilization of $\mathrm{CP}$ as partial replacement of cement may contribute to the sustainable development. It will conserve the limestone resources used in the manufacture of cement and will also help in reducing the carbon footprint associated with the cement industry. 


\section{References}

[1] Adom-Asamoah Mark, Afrifa Russell Owusu. A study of concrete properties using phyllite as coarse aggregates. Materials and design 2010;31:4561-66.

[2] Arce Carolina, Garzon Eduardo, Sanchez-Soto Pedro J. Phyllite clays as raw materials replacing cement in mortar: Properties of new impermeabilizing mortars. Construction and Building Materials 2019;224:348-358.

[3] Oliveira Thays F. de, Beck Marcia H, Escosteguy Pedro V. The effect of the substituition of hydrated lime with phyllite on mortar quality. Applied clay science 2015;105-106:113117.

[4] Morais Isabella de Souza, Magalhaes Luciano Fernades de, LaraL uis Felipe dos Santos, Correa Elaine Carballo Siqueira. Sericitic phyllite as addition in portland cement. Materials Science Forum, Transtech Publication Ltd, Switzerland 2018; ISSN:1662-9752: 930:131136.

[5] Adom-Asamoah Mark Adom-Asamoah, Afrifa Russell Owusu. Investigation on the flexural behaviour of reinforced concrete beams using phyllite aggregates from mining waste. Materials and design 2011;32:5132-5140.

[6] Garzon E, Sanchez-Soto P J, Romero E. Physical and geotechnical properties of clay phyllites. Applied clay science 2010;48: 307-18.

[7] Schulze Simone Elisabeth, Rickert Jorg. Suitability of natural calcined clay as supplementary cementitious material. Cement and Concrete Composites 2019;95:92-97. 